\title{
Climate Change: The Proof and the Process
}

\section{Rich Snow* and Mary Snow}

Professors of Meteorology, Embry-Riddle Aeronautical University, USA

Since what we call civilization began some 12,000 years ago, the mean temperature of Earth has not varied more than $1^{\circ} \mathrm{C}$ from the average. The forecast change in temperature of from 1.5 to $4^{\circ} \mathrm{C}(2.7$ to $7^{\circ} \mathrm{F}$ ) by 2100 has no equal in the recent history of the planet. Changes in the energy output of the sun, changes in the relative position of the sun and Earth, shifting locations of the continents, mountain building, volcanic eruptions, and changes in atmospheric composition all combine to cause our climate to change. Most of the changes in climate of the past can be explained by a combination of these processes. However, none of these natural changes, individually or collectively, explain the rapid change now taking place on Earth. Now these processes must be considered together with the impact of the human species. The species has grown to such an extent in numbers, and in per capita footprint, that the entire planet is being altered. That this is the case is well demonstrated by the extensive surface changes created by human activity. For instance, it has been known for decades that the human impact in cities is so great that a new set of climatic conditions is created. Now we know that the climate of the entire planet, from pole to pole, is being altered. Such extensive change has the potential to move our planet to a new stage unknown in human history and to change the entire human economic and cultural systems.

The coal, oil, and gas fields are the major sources of energy used in today's human culture to drive our industrialized world. The burning of fossil fuels adds carbon dioxide $\left(\mathrm{CO}_{2}\right)$ to the atmosphere. At the present time, the burning of organic compounds is adding far greater amounts of $\mathrm{CO}_{2}$ to the atmosphere than photosynthesis or solution in the oceans can remove. As a result, the gas is steadily increasing in the atmosphere. What we are doing today is simply reversing the process of creation of these organic compounds, which took millions of years to form. In geologic terms, we are reversing this creation in an instant. When these fuels are burned, energy is released, as are the byproducts $\mathrm{CO}_{2}$ and water vapor, into the atmosphere.

The $\mathrm{CO}_{2}$ content of the atmosphere has been increasing since at least 1850. The $\mathrm{CO}_{2}$ concentration increased from about $280 \mathrm{ppm}$ in 1850 to about $392 \mathrm{ppm}$ in 2014, which is higher than at any other time in at least the past 650,000 years. In 2007, world emissions of $\mathrm{CO}_{2}$ grew by $3 \%$ with China contributing more than half of the increase and passing the U.S. as the world's greatest contributor of greenhouse gases. The concentration is now nearly $40 \%$ more than in the pre-industrial era from 1750 to 1800 , and is increasing at an average rate of about 2.15 ppm annually.

The cause of the increase in atmospheric $\mathrm{CO}_{2}$ and ultimately for planetary warming is human activities. The main sources for the increased $\mathrm{CO}_{2}$ are the combination of burning of fossil fuels and burning of natural vegetation to clear land for agriculture. Over the past century, fossil fuel use and cement manufacturing released about 200 billion tons of carbon into the atmosphere. Current global emissions of $\mathrm{CO}_{2}$ from energy use are some 7 gigatons of carbon $(\mathrm{GtC})$ each year. By the year 2025, this is expected to increase to between 8 and $15 \mathrm{GtC}$ per year. For years beyond 2025, estimates are highly variable due to uncertainties about whether the countries with major emissions will take steps to reduce their emissions. If not, emission levels by 2100 could be five times as high as today.
Approximately $40 \%$ of $\mathrm{CO}_{2}$ placed in the atmosphere has been absorbed either by Earth's biomass or by the ocean. The remainder has accumulated in the atmosphere. Of the estimated 315 billion tons of carbon placed in the atmosphere since 1850, only 130 billion tons remain there. During the decade from 1981 to 1990, about half of the human-contributed emissions stayed in the atmosphere. Uncertainties in the size of individual sources and sinks of $\mathrm{CO}_{2}$ severely limit the accuracy of forecasts of future atmospheric concentrations. The task of predicting future abundance of atmospheric $\mathrm{CO}_{2}$ requires scientific information from many scientific disciplines. We must understand how the $\mathrm{CO}_{2}$ budget operates today. We also need to know how it responds to changes in climate and other environmental conditions. Present data suggest that $\mathrm{CO}_{2}$ emissions will grow by about $1.8 \%$ annually until 2025 and then decline to a growth rate of around $1 \%$ per year. However, $\mathrm{CO}_{2}$ emissions jumped to $3 \%$ from 2006 to 2007 . It is both possible and probable that at some time the atmospheric level will reach $400 \mathrm{ppm}$. Forecasts made in the year 2000 placed the date of reaching the 400 ppm level at the year 2025. Once the concentration reaches $400 \mathrm{ppm}$, it will be at the highest level attained in the past million years; this level is significant even in geologic time. The volume of coal known to exist in reserves is far more than necessary to produce such an increase in $\mathrm{CO}_{2}$. The amount may well double from the 1980 level in the years between 2050 and 2100. If all the known reserves of fossil fuels were burned, the $\mathrm{CO}_{2}$ content in the atmosphere would triple. Once the level goes up, it will remain there for centuries because there is no rapid means of removing it from the atmosphere.

In addition to $\mathrm{CO}_{2}$, other gases play a part in global warming. Methane is a greenhouse gas found in small amounts in the atmosphere under natural conditions. However, each methane molecule is about 21 times as efficient at absorbing Earth radiation as $\mathrm{CO}_{2}$. Methane has begun to accumulate during the past two centuries. The level of methane has risen from about 700 parts per billion (ppb) in 1750 to around 1774 $\mathrm{ppb}$ in 2005. The level nearly doubled in the 20th century. About half of the increase has occurred since 1960. The current level is the highest in at least the past 650,000 years. The additional methane comes from the raising of livestock, rice cultivation, industry, mining, and landfills. Methane rises in the atmosphere, passing through the troposphere to the stratosphere. In the stratosphere, the sun breaks down methane and the hydrogen oxidizes to form molecules of water vapor. Water vapor normally is not present in any significant amounts above the troposphere. Each methane molecule produces two water molecules. Computer models show that a doubling of methane in the atmosphere

*Corresponding author: Rich Snow, Professors of Meteorology, Embry-Riddle Aeronautical University, USA, Tel: 386-226-7104; E-mail: snow4fc@erau.edu

Received February 08, 2014; Accepted February 08, 2014; Published February 15,2014

Citation: Snow R, Snow M (2014) Climate Change: The Proof and the Process. J Climatol Weather Forecasting 2: e106. doi:10.4172/2332-2594.1000e106

Copyright: ( 2014 Snow R, et al. This is an open-access article distributed under the terms of the Creative Commons Attribution License, which permits unrestricted use, distribution, and reproduction in any medium, provided the original author and source are credited. 
should increase water vapor in the stratosphere by approximately $30 \%$. Enough water vapor exists to produce clouds made up of water and ice crystals at the cold temperatures found at heights of approximately 82 $\mathrm{km}(51 \mathrm{mi})$. These clouds reflect Earth radiation back to the surface, compounding the warming.

In latitudes from about $50^{\circ}$ to $60^{\circ}$ in the northern hemisphere, much of the land surface is covered by permafrost. In summer the surface melts, but it does not melt down far enough to thaw all the soil. The permafrost provides a barrier for gases beneath. A large amount of methane is trapped beneath this frozen soil. Because global warming is most rapid in subarctic regions, rapid melting of the permafrost is taking place in some areas and releasing methane into the atmosphere. The release of methane in sub polar regions is self-perpetuating. If more methane is released into the atmosphere, it will lead to still more warming and more methane release. On a global basis, methane is now second to $\mathrm{CO}_{2}$ in volume of emissions. It accounts for about $23 \%$ of greenhouse gases. The $\mathrm{CO}_{2}$ and methane combined account for $93 \%$ of greenhouse gas emissions.

In the short period that people have inhabited Earth in terms of geologic time, they have brought about massive changes in the environment. These changes have had a significant impact on Earth's climate. The advent of a technological society, such as that in which we now live, has created further changes. Destruction of the environment in the quest for raw materials, creation of artificial lakes, generation of energy, expansion of farmlands, urbanization, and other processes have significantly changed the face of the planet. The result of these cumulative changes is the modification of the energy interchange that occurs at the surface of Earth, and thus, climate change. 